\title{
Effect of Domain Interaction on Apolipoprotein E Levels in Mouse Brain
}

\author{
Gayathri Ramaswamy, ${ }^{1}$ Qin Xu, ${ }^{1}$ Yadong Huang, ${ }^{1,2,3}$ and Karl H. Weisgraber ${ }^{1,2,4}$ \\ ${ }^{1}$ Gladstone Institute of Neurological Disease, Departments of ${ }^{2}$ Pathology and ${ }^{3}$ Neurology, and ${ }^{4}$ Cardiovascular Research Institute, University of California, \\ San Francisco, California 94158
}

Apolipoprotein (apo) E4 is a risk factor for heart disease, Alzheimer's disease, and other forms of neurodegeneration, but the underlying mechanisms are unknown. Domain interaction, a structural property that distinguishes apoE4 from apoE2 and apoE3, results in more rapid turnover and lower plasma levels of apoE4. To determine whether domain interaction affects brain apoE levels, we analyzed brain homogenates from human apoE3 and apoE4 knock-in mice, wild-type mice, and Arg-61 apoE mice, in which domain interaction was introduced by gene targeting. As determined on Western blots, the hemibrain, cortex, hippocampus, and cerebellum of knock-in mice had 30 - 40\% lower levels of apoE4 than apoE3, and Arg-61 mice had 25-50\% lower apoE levels than wild-type mice. In the CSF, Arg-61 apoE level was 40\% lower than the wild-type level. Arg-61 apoE mRNA levels were similar to or slightly higher than wild-type apoE mRNA levels. Thus, the lower Arg-61 apoE levels were not attributable to decreased mRNA levels. In culture medium from heterozygous Arg-61/wild-type and apoE4/apoE3 primary astrocytes, Arg-61 apoE and apoE4 levels were lower than wild-type apoE and apoE3, respectively, suggesting that primary astrocytes secrete lower amounts of Arg-61 apoE and apoE4. These results demonstrate that domain interaction is responsible for the lower levels of both human apoE4 and mouse Arg-61 apoE in mouse brain. Cells may recognize apoE4 and Arg-61 apoE as misfolded proteins and target them for degradation or accumulation. Thus, degradation/accumulation or lower levels of apoE4 may contribute to the association of apoE4 with Alzheimer's disease.

Key words: apolipoprotein E; Alzheimer's disease; domain interaction; knock-in mice; wild-type mice; Arg-61 apoE mice

\section{Introduction}

Alzheimer's disease (AD), a neurodegenerative disorder whose incidence is rapidly increasing, is the leading cause of dementia in developed countries (Hebert et al., 2003). Apolipoprotein (apo) E, a plasma lipid transport protein that contains two structural domains, also plays a major role in the brain (Weisgraber and Mahley, 1996). There are three common apoE isoforms (apoE2, apoE3, and apoE4) that differ at positions 112 and 158: apoE3 contains cysteine 112 and arginine 158, whereas apoE2 has cysteines at both positions and apoE4 has arginines (Weisgraber et al., 1981). ApoE4 is associated with increased risk of late-onset familial and sporadic AD and has a gene dose effect on the risk and age of onset (Corder et al., 1993; Saunders et al., 1993; Strittmatter et al., 1993; Roses, 1996; Tang et al., 1998). It is also associated with poor outcome from head trauma, more rapid progression of multiple sclerosis and amyotrophic lateral sclerosis, and a modest increase in risk for cardiovascular disease (Utermann et al., 1984; Luc et al., 1994; Mayeux et al., 1995; Slooter et al., 1997; Teasdale et al., 1997; Drory et al., 2001; Fazekas et al.,

Received May 13, 2005; revised Sept. 19, 2005; accepted 0ct. 1, 2005.

This work was supported in part by National Institutes of Health Grants AG20235, HL37063, and C06 RR018928. We thank Belinda Bituin and Walter Brecht for excellent technical assistance, Gui-Qiu Yu and Dr. Luke Esposito for advice on real-time PCR, John Carroll and Chris Goodfellow for graphics, Stephen Ordway and Gary Howard for editorial assistance, and Karina Fantillo for manuscript preparation.

Correspondence should be addressed to Dr. Karl H. Weisgraber, Gladstone Institute of Neurological Disease, 1650 Owens Street, San Francisco, CA 94158. E-mail: kweisgraber@gladstone.ucsf.edu.

DOI:10.1523/JNEUROSCI.1922-05.2005

Copyright $\odot 2005$ Society for Neuroscience $\quad$ 0270-6474/05/2510658-06\$15.00/0
2001; Eichner et al., 2002). The exact function of apoE in the CNS is not clear.

ApoE4 has two major structural and biophysical characteristics that distinguish it from the other isoforms. One is domain interaction, an interaction between the $\mathrm{N}$ - and C-terminal domains mediated by Arg-61 and Glu-255 (Weisgraber, 1990, 1994; Dong and Weisgraber, 1996). The second is the lower stability of apoE4 and its propensity to form folding intermediates or assume a molten globule state (Morrow et al., 2002). Although domain interaction has been suggested to contribute to the detrimental effects of apoE4 in disease (Dong and Weisgraber, 1996; Weisgraber and Mahley, 1996), the existing transgenic or knock-in models cannot distinguish between the relative contributions of domain interaction versus the stability differences to the detrimental effects of apoE4.

Wild-type mouse apoE does not display domain interaction because it contains threonine rather than arginine at a position equivalent to 61 . Using gene targeting, we replaced the threonine codon with an arginine codon in wild-type mouse Apoe (Raffaï et al., 2001). Arg-61 mouse apoE has stability characteristics similar to those of wild-type apoE (Hatters et al., 2005). Therefore, the gene-targeted Arg-61 mouse is a specific model for apoE4 domain interaction. In vivo, Arg-61 apoE mouse reproduced the turnover characteristics of apoE4 in plasma, demonstrating that domain interaction occurs in this model. Heterozygous mice expressing wild-type and Arg-61 apoE had lower plasma levels of Arg-61 apoE than of wild-type apoE (Raffaï et al., 2001), indicat- 


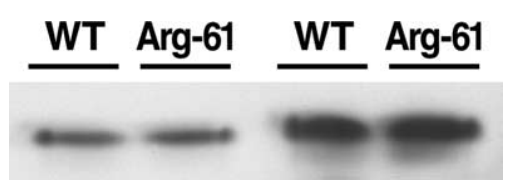

Figure 1. Specificity of mouse apoE antibody for wild-type (WT) and Arg-61 apoE. Purified mouse WT and Arg-61 apoE (250 and 500 ng) were subjected to SDS-PAGE and Western blotting with an antibody against full-length mouse apoE.

ing a more rapid turnover rate resulting from domain interaction, consistent with plasma apoE4 levels and turnover studies in humans (Gregg et al., 1986).

In this study, we sought to determine whether domain interaction also causes lower levels of apoE in the CNS. To address this question, we measured apoE protein levels in the brains of human apoE3 and apoE4 knock-in mice and wild-type and Arg-61 apoE mice.

\section{Materials and Methods}

Reagents. DMEM and fetal bovine serum were from Invitrogen (Carlsbad, CA), ECL was from Amersham Biosciences (Piscataway, NJ), goat anti-human apoE antibody was from Calbiochem (San Diego, CA), and horseradish peroxidase-coupled anti-rabbit and anti-goat IgG were from Dako (Carpinteria, CA).

Mice. Human apoE3 and apoE4 knock-in mice were from Taconic (Hudson, NY). Arg-61 apoE mice were generated as described previously (Raffaï et al., 2001) and backcrossed with wild-type C57BL/6J mice eight times.

Preparation of mouse brain tissue homogenates. Brains from human apoE knock-in, wild-type, and Arg-61 apoE mice were collected after a 3 min transcardial perfusion with PBS. One hemibrain from each mouse was analyzed separately; the other was dissected into subregions (cortex, hippocampus, and cerebellum). All tissues were homogenized in ice-cold lysis buffer (50 mm Tris- $\mathrm{HCl}, \mathrm{pH} 8.0,150 \mathrm{~mm} \mathrm{NaCl}, 0.1 \%$ SDS, $0.5 \%$ Nonidet P-40, $0.5 \%$ sodium deoxycholate, and a mixture of protease and phosphatase inhibitors) and centrifuged at $30,000 \mathrm{rpm}$ for $30 \mathrm{~min}$ at $4^{\circ} \mathrm{C}$ using a TLA 100.3 rotor in an Optima TL Ultracentrifuge (Beckman Instruments, Fullerton, CA). The supernatant was collected and analyzed for apoE.

Western blotting and quantitation of apoE levels. The supernatant (150 $\mu \mathrm{g}$ of protein) was subjected to SDS-PAGE and Western blotting. Human apoE3 and apoE4 were detected with antibody against full-length human apoE. Mouse wild-type apoE and Arg-61 apoE were detected with an antibody against recombinant, full-length wild-type mouse apoE. The protein bands were detected by chemiluminescence, using horseradish peroxidase-coupled anti-rabbit or anti-goat IgG as the secondary antibody. The blots were scanned, and the protein was quantitated by densitometry. The goat anti-human apoE antibody has equal affinity for apoE3 and apoE4 (Huang et al., 1998). The anti-mouse apoE antibody did not distinguish between the mouse isoforms (Fig. 1).

Extraction of CSF. Five-month-old heterozygous (Arg-61/wild-type apoE) mice were perfused with PBS for $7 \mathrm{~min}$. The skull was exposed and punctured with a 30 gauge needle. CSF was slowly extracted using a $1 \mathrm{ml}$ syringe connected to the needle (Raffaï et al., 2001).

Preparation of primary astrocyte-conditioned medium. Primary astrocytes from 3-d-old pups were grown to $80 \%$ confluence in medium containing DMEM and 20\% fetal bovine serum in T75 flasks. The cells were washed three times with serum-free DMEM and incubated with 5 $\mathrm{ml}$ of serum-free DMEM containing B27 supplement (Invitrogen) for $72 \mathrm{~h}$ (Fagan et al., 1999). The conditioned medium was collected and dialyzed against $0.1 \mathrm{M}$ ammonium bicarbonate for analysis of apoE levels by isoelectric focusing.

Isoelectric focusing. CSF and conditioned medium were lyophilized and delipidated in a mixture of chloroform and methanol $(2: 1, \mathrm{v} / \mathrm{v})$. The delipidated samples were dried, resuspended in sample buffer $(10 \% \mathrm{su}-$ crose, $0.1 \%$ decyl sulfate, and $0.2 \mathrm{~mm}$ Tris, $\mathrm{pH} 9.0$ ), and run on a $5 \%$ polyacrylamide gel containing $8 \mathrm{~m}$ urea and $200 \mathrm{~mm}$ ampholines, $\mathrm{pH}$

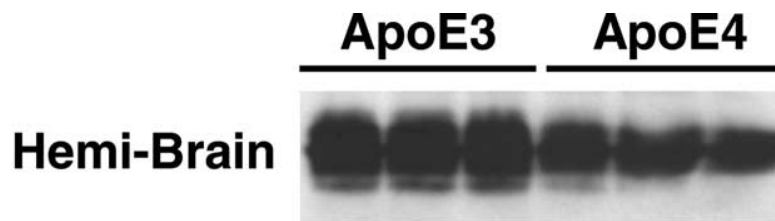

Cortex

\section{Hippocampus}

\section{Cerebellum}

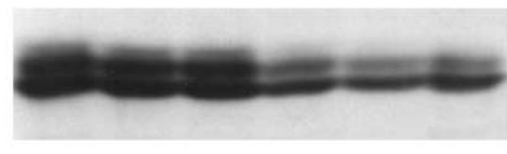

Figure 2. ApoE levels in human apoE knock-in mouse brains. The hemibrain, cortex, hippocampus, and cerebellum from 5-month-old female human apoE3 and apoE4 knock-in mice were subjected to SDS-PAGE and Western blotting with an antibody against full-length human apoE.

3.5-6.5 (Amersham Biosciences). Mouse wild-type and Arg-61 apoE and human apoE3 and apoE4 were detected and quantitated as described above.

Extraction of RNA and reverse-transcription-real-time PCR. Total RNA from brain tissue and primary astrocytes was extracted with the RNeasy kit (Qiagen, Valencia, CA). Reverse transcription was performed with 300 ng of total RNA, oligo dT, random primers, and TaqMan reverse transcription reagents (Applied Biosystems, Foster City, CA) according to the manufacturer's instructions. PCR was performed in real time with 6 ng of cDNA and the ABI PRISM-7700 sequence detector (Applied Biosystems). Mouse wild-type and Arg-61 apoE were amplified with forward primer 5'-AAGCAACCAACCCTGGGAG-3' and reverse primer $5^{\prime}$-TGCACCCAGCGCAGGTA-3'. The mouse $18 \mathrm{~s}$ gene was used as an internal standard and amplified with forward primer 5'-AGGAATTGACGGAAGGGCAC-3' and reverse primer $5^{\prime}$ GGACATCTAAGGGCATCACA-3'. Mouse apoE mRNA levels were calculated and normalized to $18 \mathrm{~s}$ mRNA.

Statistical analysis. Values are reported as mean \pm SEM. Statistical significance was determined with the $t$ test.

\section{Results}

\section{Lower brain levels of apoE4 than apoE3 in human}

knock-in mice

Levels of apoE3 and apoE4 in the brains from 5-month-old apoE3 and apoE4 knock-in mice were determined by Western blot analysis of brain homogenates (Fig. 2). Significant differences were observed between apoE3 and apoE4 levels $(p<0.01$, $n=3$ ). In the hemibrain, the apoE4 level was $28 \%$ lower than the apoE3 level. ApoE4 levels were 37\% lower in the cortex, 36\% lower in the cerebellum, and $26 \%$ lower in the hippocampus.

\section{Lower brain levels of Arg-61 apoE than wild-type apoE}

To determine whether domain interaction is responsible for the difference in apoE3 and apoE4 levels in the brains of human apoE knock-in mice, we analyzed tissue homogenates from hemibrains of 5-month-old wild-type and Arg-61 apoE mice. In female mice, the Arg-61 apoE level was 43\% lower than the wild-type apoE level (Fig. 3) $(p<0.01 ; n=6)$. Anaylsis of subregions showed that the Arg-61 apoE level was 33\% lower in the cortex, 45\% lower in the hippocampus, and 47\% lower in the cerebellum (Fig. 


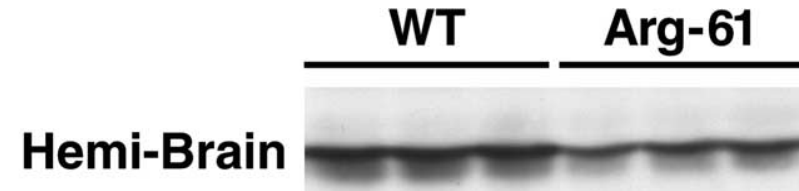

Cortex

\section{Hippocampus}

\section{Cerebellum}

Figure 3. ApoE levels in wild-type (WT) and Arg-61 apoE mouse brains. The hemibrain, cortex, hippocampus, and cerebellum from 5-month-old WT and Arg-61 apoE homozygous female mice were subjected to SDS-PAGE and Western blotting with an antibody against fulllength WT mouse apoE.

Table 1. ApoE levels in E18 embryos and 3-d-old pups

\begin{tabular}{lll}
\hline & \multicolumn{2}{l}{ Protein level relative to WT apoE } \\
\cline { 2 - 3 } & Wild type & Arg-61 \\
\hline E18 embryos $(n=6)$ & $100 \%$ & $61 \%$ \\
Three-day-old pups $(n=6)$ & $100 \%$ & $51 \%$ \\
\hline
\end{tabular}

\section{WT Arg-61 \\ Hemi-Brain (1-year-old)}

\section{Hemi-Brain (2-year-old)}

Figure 4. ApoE levels in 1- and 2-year-old wild-type (WT) and Arg-61 apoE mouse brains. The hemibrains from 1- and 2-year-old WT and Arg-61 apoE homozygous female mice were subjected to SDS-PAGE and Western blotting with an antibody to full-length mouse apoE.

3) $(p<0.01 ; n=6)$. Similar differences were observed in 5-month-old male mice (data not shown).

\section{Lower level of Arg-61 apoE is not age dependent or} gender specific

To investigate the effect of age on apoE levels, we analyzed braintissue homogenates from embryonic day 18 (E18) embryos, 3-dold pups, and 1- and 2-year-old mice. The Arg-61 apoE level was $39 \%$ lower than the wild-type level in the embryos and 49\% lower in the 3-d-old pups (Table 1). Analysis of hemibrains showed that the Arg-61 apoE level was 44\% lower in 1-year-old mice and 36\% lower in 2-year-old mice (Fig. 4$)(p<0.01 ; n=6)$. In both 1 - and 2-year-old mice, the cortical, cerebellar, and hippocampal levels of Arg-61 apoE were 25-50\% lower than those of wild-type apoE (data not shown).

To assess gender effects, we examined apoE levels in the brains of male and female mice at 5 months and 1 and 2 years of age. In

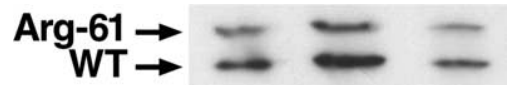

Figure 5. ApoE levels in CSF. CSF from 5-month-old heterozygous Arg-61/wild-type (WT) apoE heterozygous mice was subjected to isoelectric focusing and Western blotting.

all mice, the Arg-61 apoE levels were 25-50\% lower than the levels of wild-type apoE (data not shown), indicating that there was no gender-specific effect.

These findings demonstrate that Arg-61 apoE levels are lower than wild-type apoE levels in the brains of E18 mouse embryos and remain lower up to 2 years of age.

Arg-61 apoE level is lower than wild-type apoE level in CSF Next, the levels of wild-type and Arg-61 apoE in CSF from 5-month-old Arg-61/wild-type heterozygous mice were compared by isoelectric focusing. The Arg-61 apoE level was $40 \pm$ $2.4 \%$ lower (Fig. 5) $(p<0.01 ; n=5)$.

\section{Lower level of Arg-61 apoE is not attributable to lower} mRNA level

Next, we assessed the levels of Arg-61 and wild-type apoE mRNA in the hemibrain, cortex, hippocampus, and cerebellum from 5-month-old male and female mice. In both sexes, the levels of Arg-61 apoE mRNA were similar to or slightly higher than the levels of wild-type mRNA in the hemibrain, cortex, and hippocampus (Fig. 6). The Arg-61 and wild-type apoE mRNA levels were also similar in the cerebellum (data not shown).

Lower levels of Arg-61 apoE and apoE4 than wild-type apoE and apoE 3 in conditioned medium from primary astrocyte cultures

Differential secretion of wild-type and Arg-61 apoE by astrocytes, the major producers of apoE in the brain (Boyles et al., 1985; Pitas et al., 1987), is a potential mechanism for the lower level of Arg-61 apoE. To evaluate this possibility, we compared the amount of Arg-61 and wild-type apoE in conditioned media from primary cultures of astrocytes obtained from 3-d-old Arg61 wild-type heterozygous pups. The medium contained $45.7 \pm$ 8.4\% $(p<0.01 ; n=3)$ less Arg-61 apoE than wild-type apoE (Fig. 7A). Further analysis showed no significant difference in the levels of Arg-61 and wild-type apoE mRNA (data not shown), demonstrating that the lower amount of Arg-61 apoE in conditioned medium was not attributable to a lower mRNA level. These results suggest that the primary astrocytes secrete less Arg-61 apoE than wild-type apoE.

We also compared the levels of human apoE3 and apoE4 in the conditioned medium from heterozygous apoE3/apoE4 primary astrocyte cultures obtained from 3-d-old pups. ApoE4 levels were $\sim 24.6 \pm 3.2 \%(p<0.01 ; n=3)$ lower than apoE3 levels in the conditioned medium (Fig. $7 B$ ), suggesting that primary astrocytes secrete less apoE4 than apoE3. Together, these results indicate that domain interaction contributes to primary astrocytes secreting lower levels of human apoE4 and mouse Arg-61 apoE compared with apoE3 and mouse wild-type apoE, respectively.

\section{Discussion}

This study shows that, in the CNS, apoE4 is present at lower levels than apoE3 and Arg-61 apoE is present at lower levels than wildtype apoE. Lower levels of Arg-61 apoE were found in E18 embryos through 2 years of age. The lower levels of Arg-61 apoE 

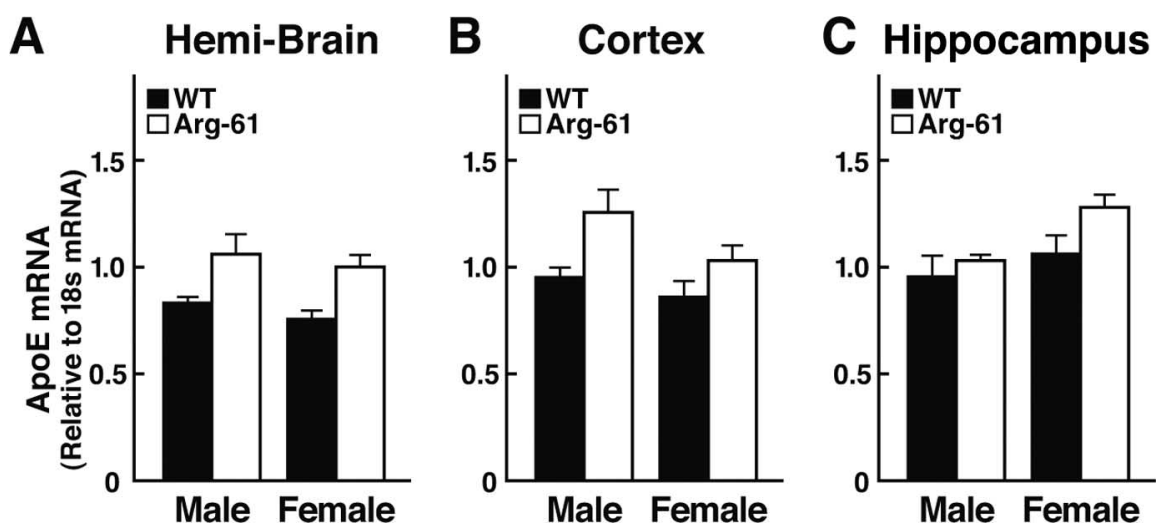

Figure 6. ApoE mRNA levels in mouse brain. Total RNA from the hemibrain $(\boldsymbol{A})$, cortex $(\boldsymbol{B})$, and hippocampus $(\boldsymbol{C})$ was extracted from 5-month-old male and female wild-type (WT) and Arg-61 apoE homozygous mice ( $n=6$ each) and analyzed for apoE mRNA levels by reverse transcription, followed by real-time PCR. The apoE mRNA levels were normalized to $18 s$ mRNA. Error bars represent values \pm SEM.

A

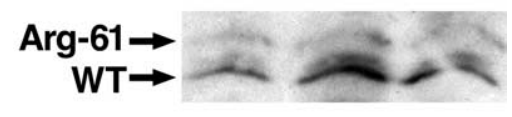

B

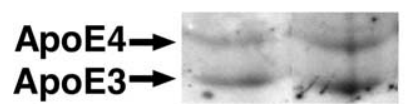

Figure 7. ApoE levels in conditioned medium from primary astrocytes. Primary astrocytes from 3-d-old Arg-61/wild-type (WT) apoE ( $\boldsymbol{A})$ and apoE4/apoE3 (B) heterozygous pups were cultured in serum-free medium for $72 \mathrm{~h}$, and the conditioned medium was subjected to isoelectric focusing and Western blotting.

were not as a result of decreased mRNA levels, suggesting a posttranslational effect. Consistent with this possibility, conditioned medium from primary astrocytes contained less Arg-61 apoE and apoE4 than wild-type apoE and apoE3, respectively.

ApoE4 levels are also lower than apoE3 levels in human plasma, reflecting the more rapid turnover of apoE4 (Gregg et al., 1986). Because of domain interaction (Dong and Weisgraber, 1996), apoE4 binds preferentially to large, triglyceride-rich, very low density lipoproteins, which are more rapidly removed from plasma than other lipoprotein classes such as high-density lipoproteins, to which apoE3 binds preferentially (Gregg et al., 1986; Steinmetz et al., 1989; Weisgraber, 1990). The Arg-61 apoE mouse model reproduces these features of apoE4 in plasma and is therefore a model for apoE4 domain interaction. The lower plasma levels of Arg-61 apoE do not stem from reduced secretion because cultured primary hepatocytes, the major source of apoE in the plasma, from heterozygous Arg-61/wild-type mice secrete similar amounts of each mouse isoform (Raffaï et al., 2001).

Because large triglyceride-rich lipoproteins are not present in the CNS, the lower levels of Arg-61 apoE cannot be explained by a more rapid clearance through this mechanism. One potential mechanism is that the cellular quality control machinery recognizes Arg-61 apoE as a misfolded protein and targets it for degradation. This would reduce secretion of the mature protein. Fluorescence resonance energy transfer studies showed that apoE4 domain interaction occurs in living cells (Xu et al., 2004). Although the exact mechanism responsible for the lower levels of apoE4 and Arg-61 apoE in mouse brains is not entirely clear, our results demonstrate that domain interaction is a major contributing factor.

Our finding of the lower levels of apoE4 than of apoE3 in knock-in mice contradicts a previous report in which equal levels of the two proteins were shown (Sullivan et al., 2004). Similarly, we found lower levels of Arg-61 apoE than of wild-type apoE in CSF from heterozygous mice. In contrast, previous studies showed higher apoE4 levels in CSF from apoE3/ apoE4 heterozygous humans (Fukumoto et al., 2003; Wahrle and Holtzman, 2003). These differences may reflect methodological differences of analysis (i.e., immunoassay versus Western blotting) and methods of extracting brain apoE.

The previous studies did not use detergents to extract brain apoE, likely leading to incomplete and variable efficiency of extraction. In addition, detergents were not included in the immunoassays, also likely leading to variable results on apoE levels. This is based on the fact that apoE is a lipid-binding protein and binds to membrane fragments, released lipids, and lipoproteins, making the extraction difficult in the absence of detergents. Even in soluble fractions, lipid binding can be problematic. This was recognized more than 20 years ago as immunoassays were being developed for quantitation of apoE in plasma. All successful apoE assays require a delipidation step using a variety of detergents (Lippel et al., 1983; Labeur et al., 1990; Krul and Cole, 1996). Epitopes on apoE3 and apoE4 can be masked to different degrees because each isoform has different preferences for lipids, making it difficult for the antibody to recognize the two proteins with equal intensity without detergent treatment. In addition, apoE tends to oligiomerize and stick to surfaces.

To avoid these problems, we used a mixture of detergents to extract apoE from the brain tissue and quantitated apoE under denaturing conditions (SDS) by Western blotting. The advantage of using detergents is that any lipid bound to apoE will be removed, making all of the epitopes on apoE equally available for recognition by the antibody. Using denaturing conditions prevents oligomerization. These strategies provide an accurate and quantitative method to determine total apoE levels in the brain. In addition, much of our data were obtained with Arg-61/wildtype and apoE4/apoE3 heterozygous mice, in which we could compare the levels of wild-type and Arg-61 apoE, and apoE3 and apoE4 in the same heterozygous mouse brain and the wild-type apoE and apoE3 served as internal controls to normalize the apoE protein level. This reduced the effect of variations between animals. Also, the possibility that the lower Arg-61 apoE level may be attributable to a specific effect of mouse apoE is ruled out because the Arg-61 apoE and the human apoE4 essentially behaved identically in the two mouse models that were examined. Lower levels of apoE4 than of apoE3 have been shown in AD brains (Bertrand et al., 1995; Beffert et al., 1999; Poirier, 2005). However, difficulty in controlling for the variation in protein level because of different stages of the disease and the low numbers of samples examined confound the interpretation.

The lower level of apoE4 than of apoE3 in the brain suggests new potential mechanisms by which apoE4 could contribute to AD. Although a gain of toxic function for apoE4 was demonstrated in transgenic mice producing apoE3 and apoE4 in neurons in a behavioral paradigm (Buttini et al., 1999), it is possible 
that apoE4 functions less effectively because it is present at lower levels with expression driven by endogenous promoters. In addition, the fraction of the apoE4, which is recognized as a misfolded protein, may be degraded into toxic fragments or accumulate as toxic aggregates. Emerging evidence indicates that apoE is expressed in neurons in response to stress (Bao et al., 1996; Metzger et al., 1996; Boschert et al., 1999; Xu et al., 1999; Harris et al., 2004), and apoE4 expressed in neurons is more susceptible than apoE3 to C-terminal cleavage, which results in the formation of cytotoxic fragments (Huang et al., 2001; Harris et al., 2003). This enhanced cleavage of apoE4 is mediated by domain interaction (Q. Xu and Y. Huang, unpublished observation). Cleavage of apoE leading to generation of these fragments in neurons in response to a stress to the brain may be an early event in the pathogenesis of AD (Huang et al., 2001; Harris et al., 2003; Brecht et al., 2004). Another possibility is that in astrocytes, domain interaction in apoE4 is recognized as a misfolded protein in the endoplasmic reticulum (ER) by the quality control machinery, activating an ER stress response pathway and targeting the protein for degradation. Alternatively, accumulation of apoE4 in the ER may lead to an ER overload response (Pahl and Baeuerle, 1997) and subsequent activation of nuclear factor $\kappa \mathrm{B}(\mathrm{NF}-\kappa \mathrm{B})$, which could have a negative impact on normal astrocyte function because of a chronic inflammatory response. Interestingly, inflammation, NF- $\kappa \mathrm{B}$ activation, and apoE have been recently connected (Ophir et al., 2005). All of these possibilities are not necessarily mutually exclusive.

In conclusion, our results demonstrate that domain interaction, which is one of the structural features distinguishing apoE4 from the other apoE isoforms, is responsible for lower levels of apoE4 in the brain. This finding emphasizes the importance of structural differences among apoE isoforms as likely contributing factors to the association of apoE4 with $\mathrm{AD}$ and other forms of neurodegeneration.

\section{References}

Bao F, Arai H, Matsushita S, Higuchi S, Sasaki H (1996) Expression of apolipoprotein $\mathrm{E}$ in normal and diverse neurodegenerative disease brain. NeuroReport 7:1733-1739.

Beffert U, Cohn JS, Petit-Turcotte C, Tremblay M, Aumont N, Ramassamy C, Davignon J, Poirier J (1999) Apolipoprotein E and $\beta$-amyloid levels in the hippocampus and frontal cortex of Alzheimer's disease subjects are disease-related and apolipoprotein E genotype dependent. Brain Res 843:87-94.

Bertrand P, Poirier J, Oda T, Finch CE, Pasinetti GM (1995) Association of apolipoprotein E genotype with brain levels of apolipoprotein $\mathrm{E}$ and apolipoprotein J (clusterin) in Alzheimer disease. Mol Brain Res 33:174-178.

Boschert U, Merlo-Pich E, Higgins G, Roses AD, Catsicas S (1999) Apolipoprotein E expression by neurons surviving excitotoxic stress. Neurobiol Dis 6:508-514.

Boyles JK, Pitas RE, Wilson E, Mahley RW, Taylor JM (1985) Apolipoprotein $\mathrm{E}$ associated with astrocytic glia of the central nervous system and with nonmyelinating glia of the peripheral nervous system. J Clin Invest 76:1501-1513.

Brecht WJ, Harris FM, Chang S, Tesseur I, Yu G-Q, Xu Q, Fish JD, WyssCoray T, Buttini M, Mucke L, Mahley RW, Huang Y (2004) Neuronspecific apolipoprotein E4 proteolysis is associated with increased tau phosphorylation in brains of transgenic mice. J Neurosci 24:2527-2534.

Buttini M, Orth M, Bellosta S, Akeefe H, Pitas RE, Wyss-Coray T, Mucke L, Mahley RW (1999) Expression of human apolipoprotein E3 or E4 in the brains of Apoe $e^{-1-}$ mice: isoform-specific effects on neurodegeneration. J Neurosci 19:4867-4880.

Corder EH, Saunders AM, Strittmatter WJ, Schmechel DE, Gaskell PC, Small GW, Roses AD, Haines JL, Pericak-Vance MA (1993) Gene dose of apolipoprotein E type 4 allele and the risk of Alzheimer's disease in late onset families. Science 261:921-923.

Dong L-M, Weisgraber KH (1996) Human apolipoprotein E4 domain in- teraction. Arginine 61 and glutamic acid 255 interact to direct the preference for very low density lipoproteins. J Biol Chem 271:19053-19057.

Drory VE, Birnbaum M, Korczyn AD, Chapman J (2001) Association of $A P O E \epsilon 4$ allele with survival in amyotrophic lateral sclerosis. J Neurol Sci 190:17-20.

Eichner JE, Dunn ST, Perveen G, Thompson DM, Stewart KE, Stroehla BC (2002) Apolipoprotein E polymorphism and cardiovascular disease: a HuGe review. Am J Epidemiol 155:487-495.

Fagan AM, Holtzman DM, Munson G, Mathur T, Schneider D, Chang LK, Getz GS, Reardon CA, Lukens J, Shah JA, LaDu MJ (1999) Unique lipoproteins secreted by primary astrocytes from wild type, apoE $(-/-)$, and human apoE transgenic mice. J Biol Chem 274:30001-30007.

Fazekas F, Strasser-Fuchs S, Kollegger H, Berger T, Kristoferitsch W, Schmidt H, Enzinger C, Schiefermeier M, Schwarz C, Kornek B, Reindl M, Huber K, Grass R, Wimmer G, Vass K, Pfeiffer KH, Hartung HP, Schmidt R (2001) Apolipoprotein $\mathrm{E} \epsilon 4$ is associated with rapid progression of multiple sclerosis. Neurology 57:853-857.

Fukumoto H, Ingelsson M, Gårevik N, Wahlund L-O, Nukina N, Yaguchi Y, Shibata M, Hyman BT, Rebeck GW, Irizarry MC (2003) APOE $\epsilon 3 / \epsilon 4$ heterozygotes have an elevated proportion of apolipoprotein E4 in cerebrospinal fluid relative to plasma, independent of Alzheimer's disease diagnosis. Exp Neurol 183:249-253.

Gregg RE, Zech LA, Schaefer EJ, Stark D, Wilson D, Brewer Jr HB (1986) Abnormal in vivo metabolism of apolipoprotein $\mathrm{E}_{4}$ in humans. J Clin Invest 78:815-821.

Harris FM, Brecht WJ, Xu Q, Tesseur I, Kekonius L, Wyss-Coray T, Fish JD, Masliah E, Hopkins PC, Scearce-Levie K, Weisgraber KH, Mucke L, Mahley RW, Huang Y (2003) Carboxyl-terminal-truncated apolipoprotein E4 causes Alzheimer's disease-like neurodegeneration and behavioral deficits in transgenic mice. Proc Natl Acad Sci USA 100:10966-10971.

Harris FM, Tesseur I, Brecht WJ, Xu Q, Mullendorff K, Chang S, Wyss-Coray T, Mahley RW, Huang Y (2004) Astroglial regulation of apolipoprotein E expression in neuronal cells. Implications for Alzheimer's disease. J Biol Chem 279:3862-3868.

Hatters DM, Peters-Libeu CA, Weisgraber KH (2005) Engineering conformational destabilization into mouse apolipoprotein $\mathrm{E}$ : a model for a unique property of human apolipoprotein E4. J Biol Chem 280:2647726482.

Hebert LE, Scherr PA, Bienias JL, Bennett DA, Evans DA (2003) Alzheimer disease in the US population. Prevalence estimates using the 2000 census. Arch Neurol 60:1119-1122.

Huang Y, Liu XQ, Rall Jr SC, Taylor JM, von Eckardstein A, Assmann G, Mahley RW (1998) Overexpression and accumulation of apolipoprotein $\mathrm{E}$ as a cause of hypertriglyceridemia. J Biol Chem 273:26388-26393.

Huang Y, Liu XQ, Wyss-Coray T, Brecht WJ, Sanan DA, Mahley RW (2001) Apolipoprotein $\mathrm{E}$ fragments present in Alzheimer's disease brains induce neurofibrillary tangle-like intracellular inclusions in neurons. Proc Natl Acad Sci USA 98:8838-8843.

Krul ES, Cole TG (1996) Quantitation of apolipoprotein E. Methods Enzymol 263:170-187.

Labeur C, Shepherd J, Rosseneu M (1990) Immunological assays of apolipoproteins in plasma: methods and instrumentation. Clin Chem 36:591-597.

Lippel K, Tyroler HA, Gotto Jr A, Brewer HB, Albers JJ, Scanu A, Alaupovic P (1983) Workshop on apolipoprotein quantification. Arteriosclerosis 3:452-464.

Luc G, Bard J-M, Arveiler D, Evans A, Cambou J-P, Bingham A, Amouyel P, Schaffer P, Ruidavets J-B, Cambien F, Fruchart J-C, Ducimetiere P (1994) Impact of apolipoprotein E polymorphism on lipoproteins and risk of myocardial infarction. The ECTIM study. Arterioscler Thromb 14:1412-1419.

Mayeux R, Ottman R, Maestre G, Ngai C, Tang M-X, Ginsberg H, Chun M, Tycko B, Shelanski M (1995) Synergistic effects of traumatic head injury and apolipoprotein- $\epsilon 4$ in patients with Alzheimer's disease. Neurology 45:555-557.

Metzger RE, LaDu MJ, Pan JB, Getz GS, Frail DE, Falduto MT (1996) Neurons of the human frontal cortex display apolipoprotein $\mathrm{E}$ immunoreactivity: implications for Alzheimer's disease. J Neuropathol Exp Neurol 55:372-380. 
Morrow JA, Hatters DM, Lu B, Höchtl P, Oberg KA, Rupp B, Weisgraber KH (2002) Apolipoprotein E4 forms a molten globule: a potential basis for its association with disease. J Biol Chem 277:50380-50385.

Ophir G, Amariglio N, Jacob-Hirsch J, Elkon R, Rechavi G, Michaelson DM (2005) Apolipoprotein E4 enhances brain inflammation by modulation of the NF- $\kappa \mathrm{B}$ signaling cascade. Neurobiol Dis, in press.

Pahl HL, Baeuerle PA (1997) The ER-overload response: Activation of NF$\kappa \mathrm{B}$. Trends Biochem Sci 22:63-67.

Pitas RE, Boyles JK, Lee SH, Foss D, Mahley RW (1987) Astrocytes synthesize apolipoprotein $\mathrm{E}$ and metabolize apolipoprotein E-containing lipoproteins. Biochim Biophys Acta 917:148-161.

Poirier J (2005) Apolipoprotein E, cholesterol transport and synthesis in sporadic Alzheimer's disease. Neurobiol Aging 26:355-361.

Raffaï RL, Dong L-M, Farese Jr RV, Weisgraber KH (2001) Introduction of human apolipoprotein E4 "domain interaction" into mouse apolipoprotein E. Proc Natl Acad Sci USA 98:11587-11591.

Roses AD (1996) Apolipoprotein E alleles as risk factors in Alzheimer's disease. Annu Rev Med 47:387-400.

Saunders AM, Strittmatter WJ, Schmechel D, St George-Hyslop PH, PericakVance MA, Joo SH, Rosi BL, Gusella JF, Crapper-MacLachlan DR, Alberts MJ, Hulette C, Crain B, Goldgaber D, Roses AD (1993) Association of apolipoprotein E allele $\epsilon 4$ with late-onset familial and sporadic Alzheimer's disease. Neurology 43:1467-1472.

Slooter AJC, Tang M-X, van Duijn CM, Stern Y, Ott A, Bell K, Breteler MMB, Van Broeckhoven C, Tatemichi TK, Tycko B, Hofman A, Mayeux R (1997) Apolipoprotein E $\epsilon 4$ and the risk of dementia with stroke. A population-based investigation. J Am Med Assoc 277:818-821.

Steinmetz A, Jakobs C, Motzny S, Kaffarnik H (1989) Differential distribution of apolipoprotein $\mathrm{E}$ isoforms in human plasma lipoproteins. Arteriosclerosis 9:405-411.

Strittmatter WJ, Saunders AM, Schmechel D, Pericak-Vance M, Enghild J, Salvesen GS, Roses AD (1993) Apolipoprotein E: high-avidity binding to $\beta$-amyloid and increased frequency of type 4 allele in late-onset familial Alzheimer disease. Proc Natl Acad Sci USA 90:1977-1981.

Sullivan PM, Mace BE, Maeda N, Schmechel DE (2004) Marked regional differences of brain human apolipoprotein E expression in targeted replacement mice. Neuroscience 124:725-733.

Tang M-X, Stern Y, Marder K, Bell K, Gurland B, Lantigua R, Andrews H, Feng L, Tycko B, Mayeux R (1998) The APOE- $\epsilon 4$ allele and the risk of Alzheimer disease among African Americans, whites, and Hispanics. J Am Med Assoc 279:751-755.

Teasdale GM, Nicoll JAR, Murray G, Fiddes M (1997) Association of apolipoprotein E polymorphism with outcome after head injury. Lancet 350:1069-1071.

Utermann G, Hardewig A, Zimmer F (1984) Apolipoprotein E phenotypes in patients with myocardial infarction. Hum Genet 65:237-241.

Wahrle SE, Holtzman DM (2003) Differential metabolism of apoE isoforms in plasma and CSF. Exp Neurol 183:4-6.

Weisgraber KH (1990) Apolipoprotein E distribution among human plasma lipoproteins: role of the cysteine-arginine interchange at residue 112. J Lipid Res 31:1503-1511.

Weisgraber KH (1994) Apolipoprotein E: Structure-function relationships. Adv Protein Chem 45:249-302.

Weisgraber KH, Mahley RW (1996) Human apolipoprotein E: the Alzheimer's disease connection. FASEB J 10:1485-1494.

Weisgraber KH, Rall Jr SC, Mahley RW (1981) Human E apoprotein heterogeneity. Cysteine-arginine interchanges in the amino acid sequence of the apo-E isoforms. J Biol Chem 256:9077-9083.

Xu P-T, Gilbert JR, Qiu H-L, Ervin J, Rothrock-Christian TR, Hulette C, Schmechel DE (1999) Specific regional transcription of apolipoprotein E in human brain neurons. Am J Pathol 154:601-611.

Xu Q, Brecht WJ, Weisgraber KH, Mahley RW, Huang Y (2004) Apolipoprotein E4 domain interaction occurs in living neuronal cells as determined by fluorescence resonance energy transfer. J Biol Chem 279:2551125516. 